\title{
AUTOMATIC IRRIGATION AND WEATHER MONITORING SYSTEM USING IOT
}

\author{
M Sri Phanindra Sarma ${ }^{1}$, Ravi Kumar C V ${ }^{2}$, Kalapraveen Bagadi ${ }^{3}$ \\ ${ }^{1,2,3}$ School of Electronics Engineering, VIT University Vellore-632014, Tamil Nadu, India \\ 1sriphanindrasarma1@gmail.com, ${ }^{2}$ ravikumar.cv@vit.ac.in, ${ }^{3}$ bkpraveen@vit.ac.in
}

\begin{abstract}
Monitoring the electric water pump through internet of things (IOT) is the main objective of this project. Today, in this modern and developing world everyone wants their needs to be fulfilled in more feasible way at the same time with maximum efficiency. Growth in technology made humans to search for new methods where one could meet the same old requirements with less human effort. The process of switching ON or OFF of a motor has become a problem. It has become very difficult for us to look after the motor every time, to overcome this situation we have come up with an idea of using IOT. The switching ON and OFF of the motor is done with the sensor which we have integrated along. The sensor will automatically switch on when the moisture of the soil goes down below preset value and switches off automatically, as required for a specified crop/soil. This not only efficiencies the crop, but also saves electricity as well time. to ease of use. It also takes the surrounding environment conditions like temperature and uploads directly to the server.
\end{abstract}

Keywords: Raspberry Pi 3, Soil Moisture, Temperature, IOT

\section{INTRODUCTION}

Internet and mobiles have become part and parcel of day-today life, which enables communication and management of personal information from anywhere and at any time. Internet appears everywhere in the world but it is still a connection between people and people. Internet connects all the people, so it is "Internet of People". IOT connects all the things so it is "Internet of Things". The term "Internet of Things" has come to describe a number of technologies and research disciplines that enable the Internet to reach out into the real world of physical objects.

Today the world is facing such an environment that has challenges. Energy crisis is the serious problem faced by our society. A relevant system to control and monitor the power usage is one of the solutions for this serious threat. One approach through which today's energy crisis can be addressed is through the reduction of power usage in households. This can be achieved if we provide a solution that helps the user to monitor the soil moisture and to switch on or off the motor accordingly. It is necessary to provide an effective to this problem which is possible through IoT.

\section{PROPOSED SYSTEM}

The proposed system has a Raspberry pi and few sensors, which would calculate the values and will upload to server.

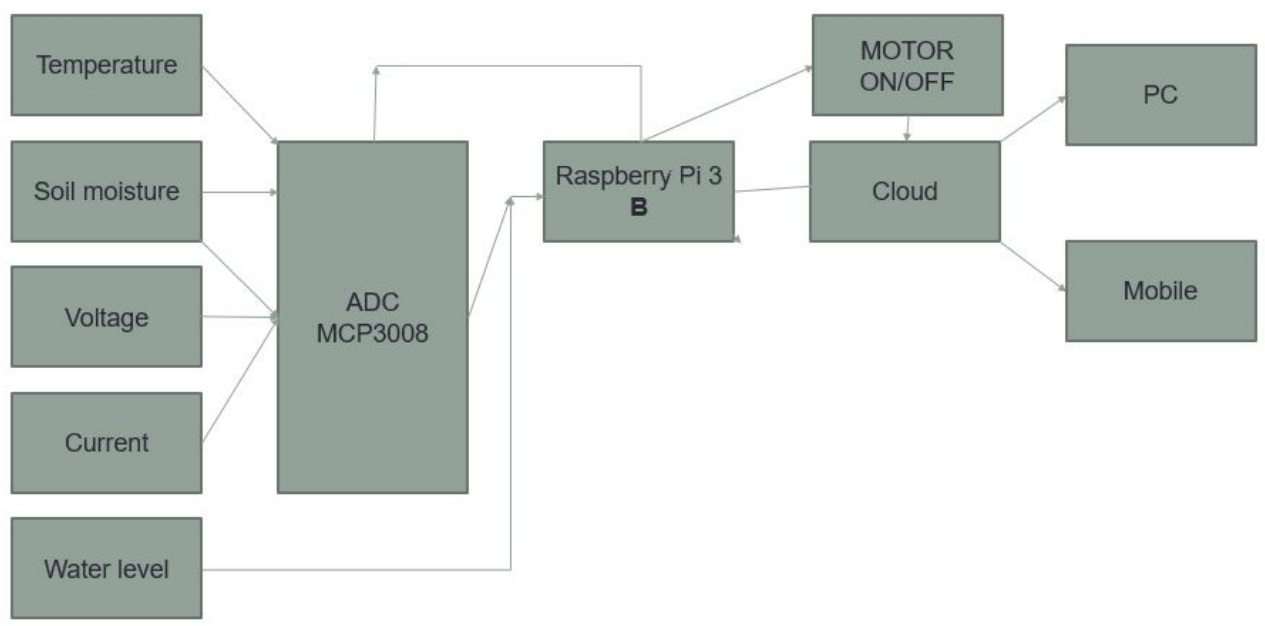

Fig.1 Block Diagram of Proposed System. 
The data obtained from the temperature sensor, soil moisture sensor, and ultrasonic sensor is sent to Analog to Digital converter (MCP3008) and then sent to the raspberry pi which is the main part of the project. This data is processed by the raspberry pi and will be displayed on the Lx terminal. The processing of the data obtained from the sensor is done by writing a code in python language. The final values is put on the web page which is designed through HTML script in notepad++ editor. Here, we have used a third-party site to display the data. Therefore, we need to type the address of the third-party site to view the reading on the webpage. So everything is connected and can be controlled through IOT.

Raspberry Pi 3 model B is used. It is a series of credit-card sized single board on-chip computers developed in England. The Raspberry Pi 3 delivers 6 times the processing capacity of previous models. This second generation RPi has an upgraded Broadcom BCM2837 processor, which is a powerful ARMv8 based quad-core processor that runs at $1.2 \mathrm{GHz}$. The board also features an increase in memory capacity to 1 Gbyte. Different products were present like raspberry pi model $\mathrm{A}, \mathrm{A}+, \mathrm{B}, \mathrm{B}+$, zero. All these products are basically differ according to their specifications which were improved year after year.

\section{METHODOLOGIES ADOPTED}

A. Interfacing the sensor with the ADC and to RSPi and obtaining the data from it.

Project begins by installing OS in the memory stick. Two operating systems are available in Raspberry Pi official website. Once OS is installed all other features like Apache server, Php, requests, pip are updated. After all up-gradation is done Raspberry Pi is ready to work with. The Raspberry $\mathrm{Pi}$ is initially made to set up in such a way that it can be easily used according to our purposes. The Soil moisture sensor module, temperature sensor module, ultrasonic sensor module is connected to the ADC(MCP3008) and then to Raspberry Pi using the GPIO pins of the Pi. The sensors are connected using a breadboard to the Raspberry Pi in such a way that the required output is obtained from one of the GPIO connected to the sensor. There are 4 pins for soil moisture sensor.

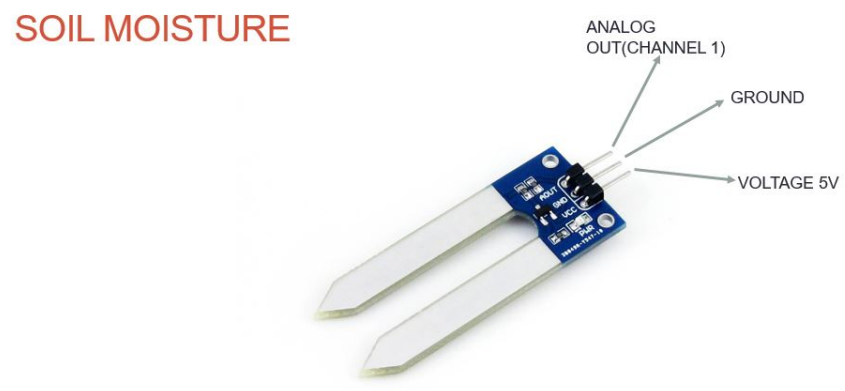

Fig.1. Soil moisture sensor connections with ADC

\section{Temperature Sensor}

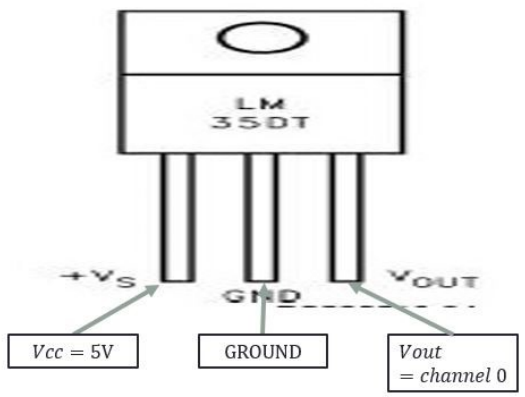

Fig.2. Temperature sensor connections with ADC

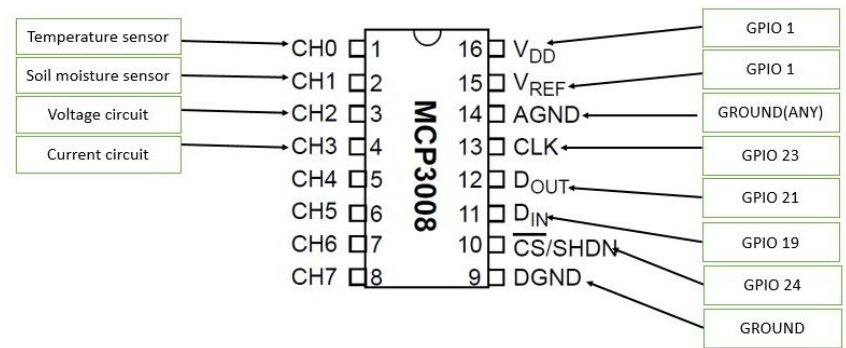

Fig.3. Connections of ADC

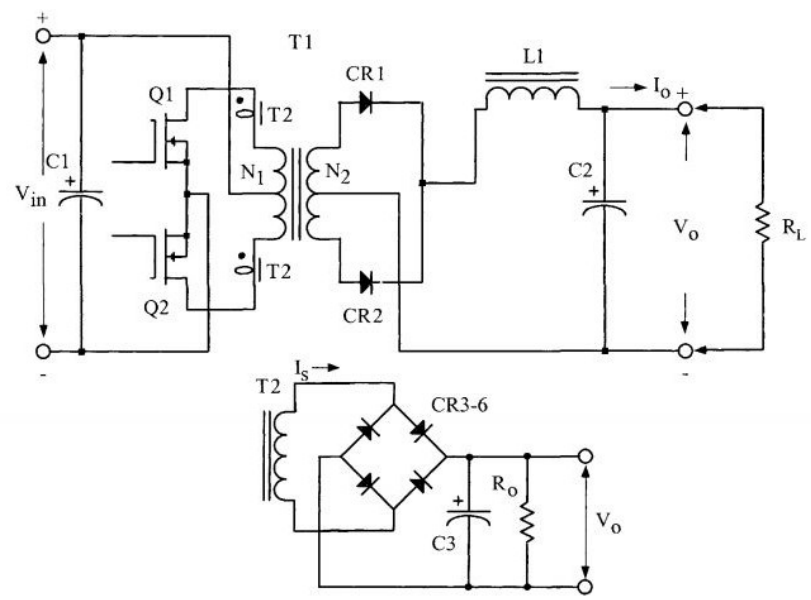

Fig 4. Current calculation circuit.

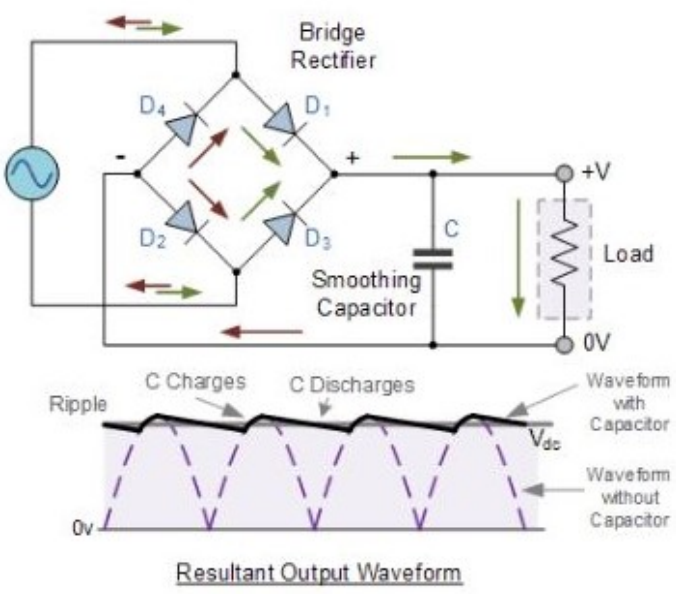

Fig 5. Voltage calculation circuit 
The values for the soil moisture sensor, and the temperature sensor are been calibrated in analog, the values which Raspberry Pi takes is only digital values. So in order to convert analog to digital values, we used ADC(mcp3008). Here we have used SPI (serial peripheral interface) protocol, to get the values from sensors to the Rpi. This $\mathrm{ADC}$ is a 8 bit resolution microchip which has 8 different channels. so far we used only 4 channels one to each of the above mentioned 4 modules. In order to measure the power consumed by the motor, we have used the following techniques. The voltage measured by stepping down the $240 \mathrm{~V}$ to $12 \mathrm{~V}$ using step down transformer and then this 12 volts is further brought down to $3.3 \mathrm{~V}$ by bridge rectifier circuit. The current consumed by the motor is also been Calculated in the same way, by using a current transformer, and a bridge rectifier circuit. Then this is connected to one of the channel of ADC. Once the coding is done in the python language it is executed on Lx terminal and the required values are displayed.

\section{B. Interfacing the ultra sonic senor(to calculate the liquid level)}

There are four pins in ultrasonic sensor namely Vcc, Trigger, Echo and Ground. The GPIO pins re connected to the sensor as shown in the figure above and the values are calculated by the difference in time between the transmitting and receiving of wave the required time is calculated. The value obtained is multiplied with speed of sound in $\mathrm{cm} / \mathrm{sec}$ and it is halved as the distance in only one way is needed.

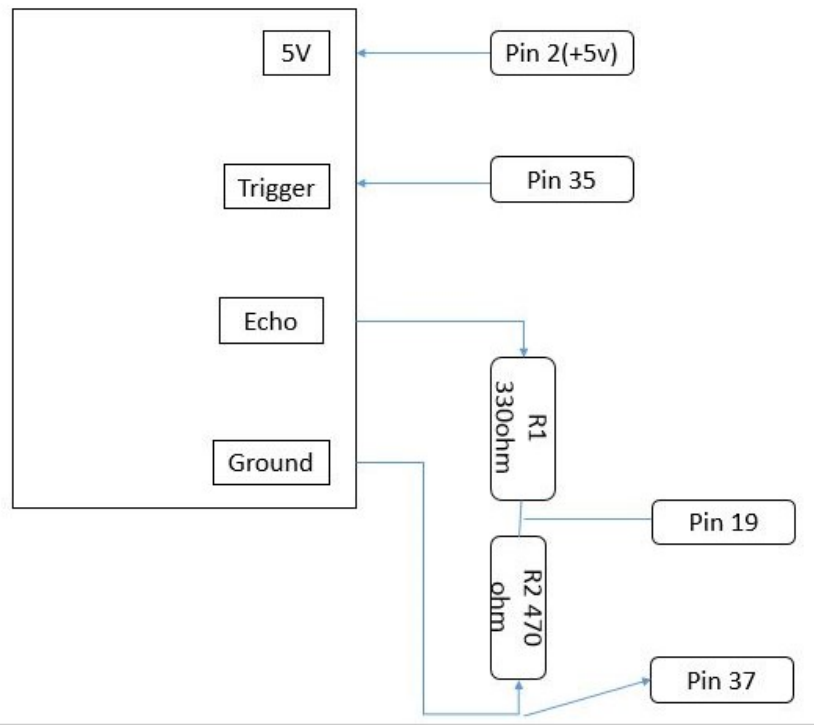

Fig 6. Ultra sonic Sensor connections with Raspberry Pi.

\section{Controlling the electric motor(water pump)}

The pump is controlled automatically when the device and Raspberry pi are on same network. When the soil moisture is less than $40 \%$ it triggers ON. Else it switches OFF. As the $230 \mathrm{~V}$ AC motor cannot be used a $12 \mathrm{~V}(15 \mathrm{~W})$ DC water pump is used here to show the working of the project. As the relay is used if the motor runs, then the field motor with a supply of $230 \mathrm{~V}$ AC can also work.

\section{RESULTS}

The soil Moisture sensor The soil moisture sensor is connected to the corresponding ADC channel and GPIO pin of the Raspberry Pi. The Raspberry Pi can be connected to the laptop using the Ethernet cable. Finally the motor is connected to the Raspberry Pi using a relay which acts as a switch and helps us to turn ON/OFF the motor using IoT. The complete system is as shown.

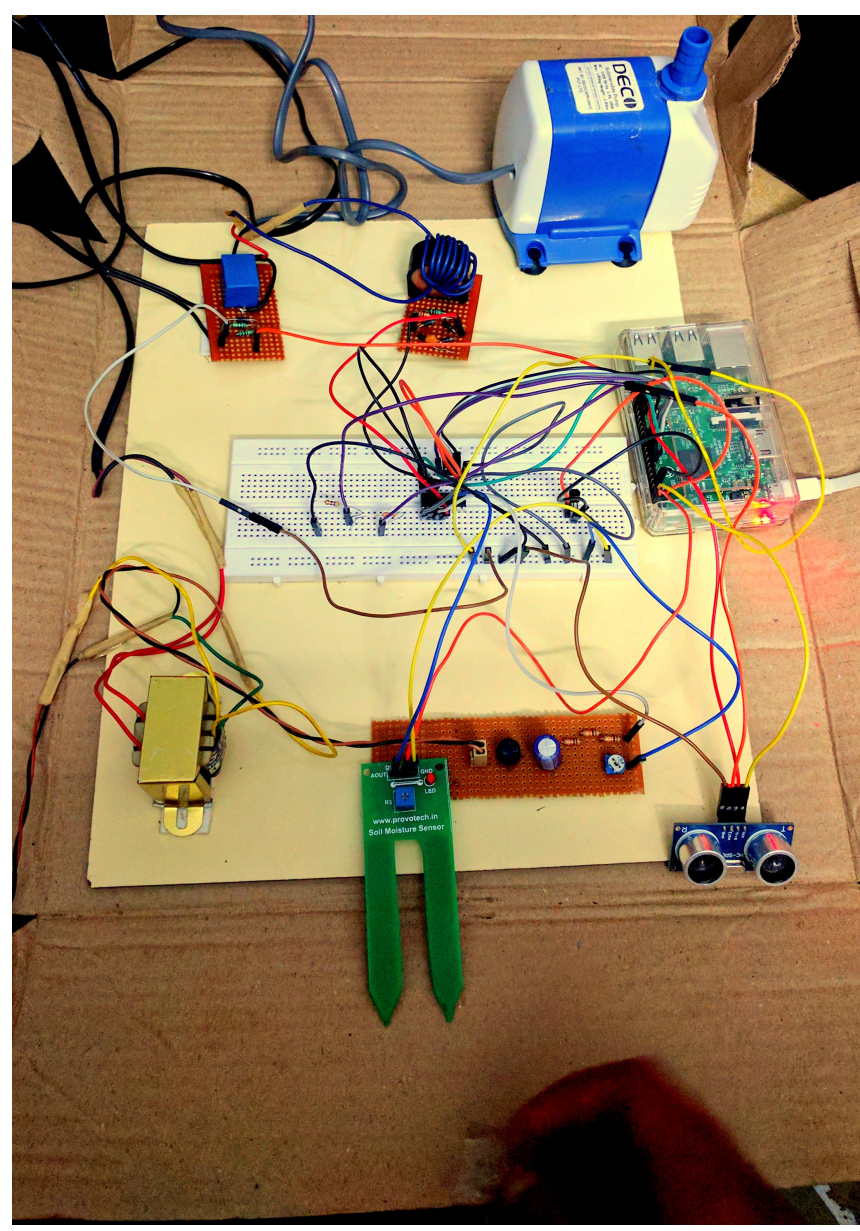

Fig 7. Complete project setup.

After python program is compiled the following is the output. 


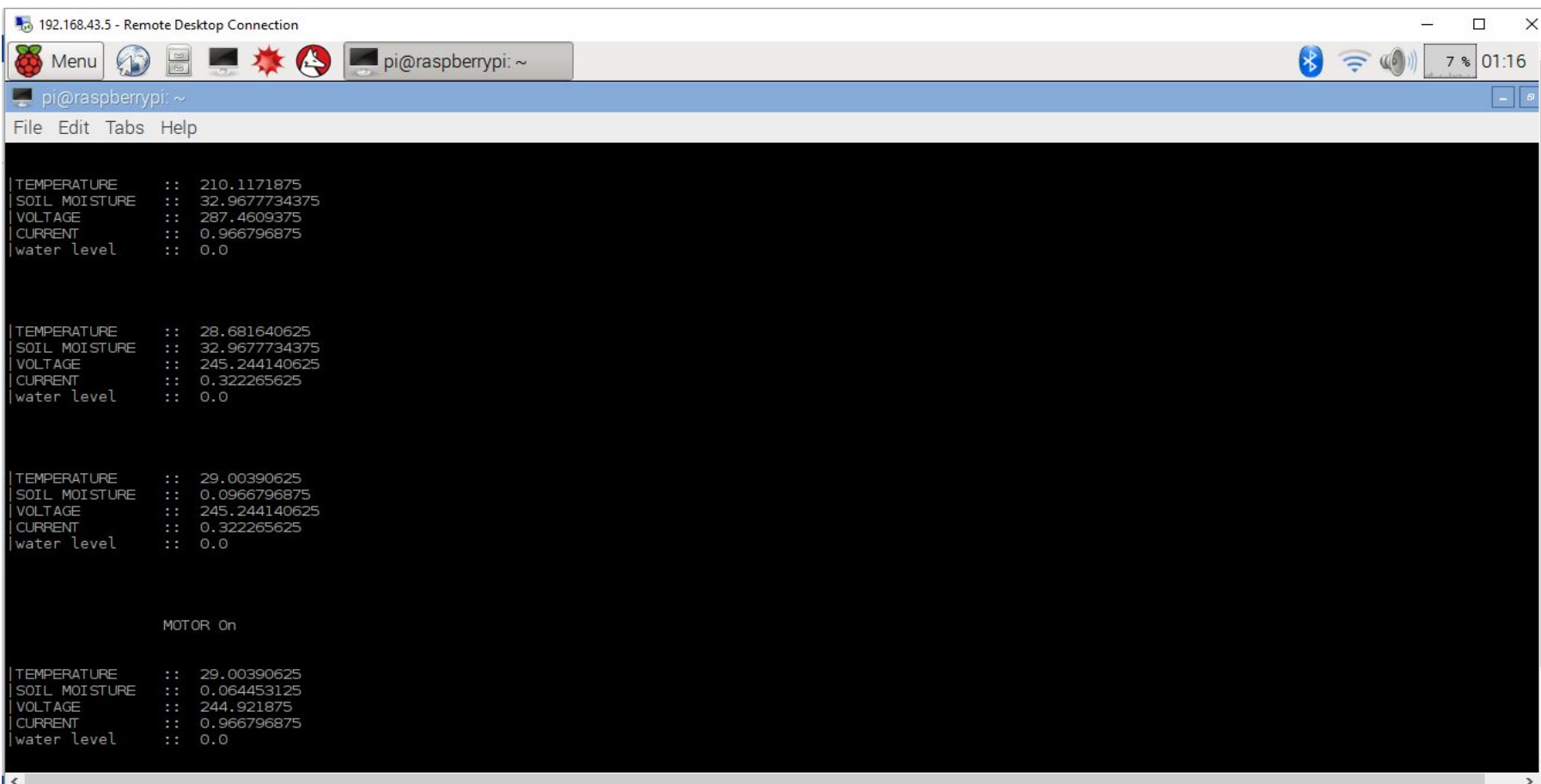

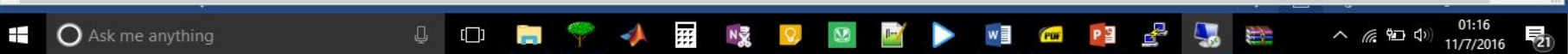

Fig 8. shows where the motor is in OFF state.

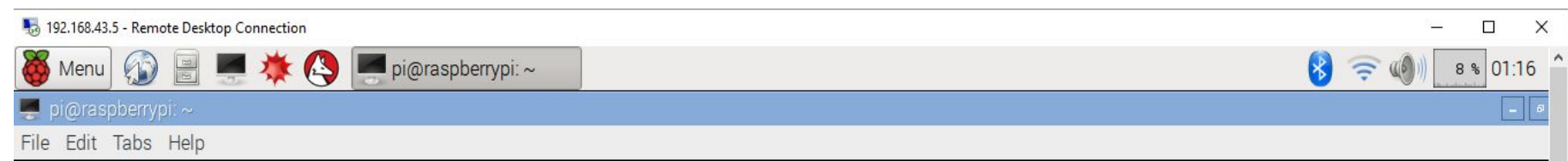

MOTOR On

TEMPERATURE $\quad:: 29.00390625$

SOIL MOISTURE $\quad:: \frac{0.064453125}{::}$

$\begin{array}{lll}\text { VOLTAGE } & :: & 244.921875 \\ \text { CURRENT } & :: & 0.966796875\end{array}$

CURREN $\quad: \quad:: 0.9607$

MOTOR On

TEMPERATURE $\quad:: 29.00390625$

SOIL MOISTURE $\quad:: 1.998046875$

$\begin{array}{lll}\text { VOLTAGE } & :: 244.59960937 \\ \text { CURPENT } & :: & 1.2890625\end{array}$

$\begin{array}{lll}\text { CURRENT } & :: & 1.2890625 \\ \text { water level } & :: & 55.1619104147\end{array}$

MOTOR On

TEMPERATURE $\quad:: 29.00390625$

SOIL MOISTURE $\quad::: 1.9013671875$

VOLTAGE $\quad:: 245.244140625$

water level

0.322265625

58.9203922749

* O Ask me anything

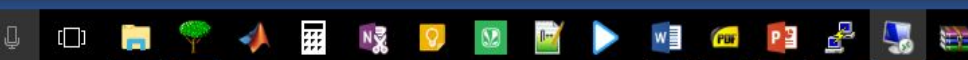

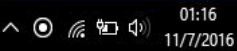

Fig 9. shows where the motor is in $\mathrm{ON}$ state.

\section{CONCLUSION}

In this we proposed the best way to observe and controlling the motor by itself automatically with the soil moisture sensor being on when the water level in the soil drops below some certain value and switches off after reaching the maximum value. With this prototype, we can aswell know the atmospheric temperature. And also we can also know the power drawn from the motor every week/month/year etc. depending upon the required need. 


\section{ACKNOWLEDGMENT}

I am using this opportunity to express our deepest gratitude and would like to give a special thanks to our project guide, Prof. Ravi Kumar C V, who in spite of being extraordinarily busy with his duties, took time out to hear, guide and keep us on the correct path and for allowing us to carry out our project at this university.

\section{REFERENCES}

[1] International journal of VLSI and Embedded Systems (IJVES) Advance technique for soil moisture content based automatic motor pumping for agricultural land purpose Sanjukumar ${ }^{1}$, Krishnaiah R.V ${ }^{2}$ ISSN : 2249 6556

[2] International Conference for convergence of technology - Real Time Automation of Agricultural Environment. Patil Prachi ${ }^{1}$, Narkhede Akshay $^{2}$, Ajitha Chalke ${ }^{3}$, Harshali Kalaskar ${ }^{4}$, Manita Rajput ${ }^{5}$

[3] AE International Journal of Science and Technology vol 2 Issue 1 - Microcontroller based automation of drip irrigation system. S. Mahendra ${ }^{1}$, M. Lakshmana Bharathi ${ }^{2}$.

[4] Low Power Wireless Liquid monitoring System Using Ultrasonic Sensors.

[5] (International Journal on Smart Sensing and Intelligent Systems Vol.8, No.1, March 2015)

[6] Remote Access of Raspberry Pi, Raspberry Pi Available:

https://www.raspberrypi.org/documentation/remoteaccess/

[7] Water Tank Monitoring and Visualization System Using Smart-Phones

[8] (International Journal of Machine Learning and Computing, Vol.3, No. 1, February 2013)

[9] Alex Bradbury, Ben Everard (2014). Interfacing with Hardware, Learning Python with Raspberry Pi.

[10] Raspberry Pi GPIO-LED on/off (wiring pi+PHP) http://kurup87.blogspot.in/2014/09/raspberry-pi-gpioled-onoff- wiring-pi.html 